\title{
Development of technology for brazing and diffusion welding of copper accelerating structures
}

\author{
Vardan Avagyan \\ Center for the Advancement of Natural Discoveries using Light Emission, Avan, Acharian 31, 375040 Yerevan, Armenia
} (Received 14 April 2006; published 25 August 2006)

\begin{abstract}
This work presents technologies of copper accelerating structure diffusion joints. The formation conditions of copper diffusion joint with the minimal residual plastic strain are determined experimentally.
\end{abstract}

DOI: 10.1103/PhysRevSTAB.9.083501

PACS numbers: 81.20.Vj, 29.17.+w

\section{INTRODUCTION}

The problem of the preservation of precision beams of high-energy charged particles in modern linear accelerators imposes stringent requirements on the quality of manufacturing and mounting of copper accelerating structures. All those requirements are aimed to minimize nonuniformities inside accelerating structure cavities and admixtures during copper parts brazing and strains while joining structural parts. That mentioned above shows the evident actuality of the problem of the creation of new safe methods of precise elements joining [1,2].

While joining the accelerating structure elements, it is necessary to meet the following requirements: (i) provision of joint strength, (ii) provision of vacuum Hermiticity, (iii) provision of design geometrical dimensions of the accelerating structure, (iv) minimization of residual strains after joining the structure elements, (v) avoidance of various admixtures, oxidation and formation of new compounds, and (vi) development of a facility for the joining of the accelerating structure separate parts.

Important problems for the technical realization of those requirements is the ensuring of the same joining conditions for each cell joint in the accelerating structure and the development of the copper constructions joining the facility that would provide the fulfillment of the abovementioned requirements.

The present paper considers joining of the accelerating structures by diffusion welding in vacuum. The questions regarding the dependence of the residual strain of joining parts of the accelerating section on pressure, temperature, and process time have been investigated. A facility for diffusion welding of accelerating sections providing the minimal plastic strain of the joining items has been developed.

\section{TECHNOLOGY OF THE ACCELERATING STRUCTURE DIFFUSION BRAZING}

The accelerating structure consists of separate elements made of copper bowls, which are assembled in a package and brazed one with another by a silver solder $(72 \% \mathrm{Ag}$, $28 \% \mathrm{Cu}$ ) in a vacuum environment (see e.g. [3]). During the brazing process of constructive parts, the geometric shape of the construction on the mating area may become deformed due to the thickness of spreading silver layer [4].

To provide the required electric parameters of accelerating structures and good wetting of the solder, it is proposed to preliminarily coat cell junctions with silver by the galvanic plating method.

The application of the galvanic silver (which is softer than copper) as an intermediate part results in localization of the plastic compressive strain on the mating spot of the item. The physical contact is formed mainly due to silver active deformation and creep, which fills in the microasperities of joining surfaces and considerably reduces the required compression pressure and residual strain of items. While joining two copper samples through a thin layer of silver at the temperature slightly higher than the melting temperature of $\mathrm{Ag}-\mathrm{Cu}$ eutectic (but remaining below the melting temperature of silver), the process of contact-reactive brazing (when the solder formed as a result of a contact-reactive melting) is developed. It is based on the property of some metals to form an alloy (eutectic or solid alloy) in the contact area, the melting point of which is lower than the melting points of each joining metal. Compression pressure on joining details, which impact on the physiochemical processes occurring on the contact spot, is very important. As it is known from the copper-silver system equilibrium diagram, silver has limited solubility in copper (less than 8\%) and therefore the galvanic coating thickness should be minimal. Experimental studies showed that the optimal coating thickness should be about $8-12 \mu \mathrm{m}$. A further increase of coating thickness results in the strength reduction of the joint and in the increase of residual strain.

Joining of copper accelerating structures has been carried out in vacuum $P=1.3 \times 10^{-3} \mathrm{~Pa}$ at the temperature of $1073 \mathrm{~K}$ and compression pressure of $1 \mathrm{MPa}$. Figure 1 schematically presents a facility for joining the accelerating structure with a length of up to $1.2 \mathrm{~m} \mathrm{[5].}$

The developed facility enables one to provide optimum performance of joining at the junction of each two cells along the full length of the accelerating structure. Constancy of pressure is provided by the control system of a magnet, which decreases the load during the heater top-down travel (taking into account the weight of the cell, which is important for reduction of deformation during 


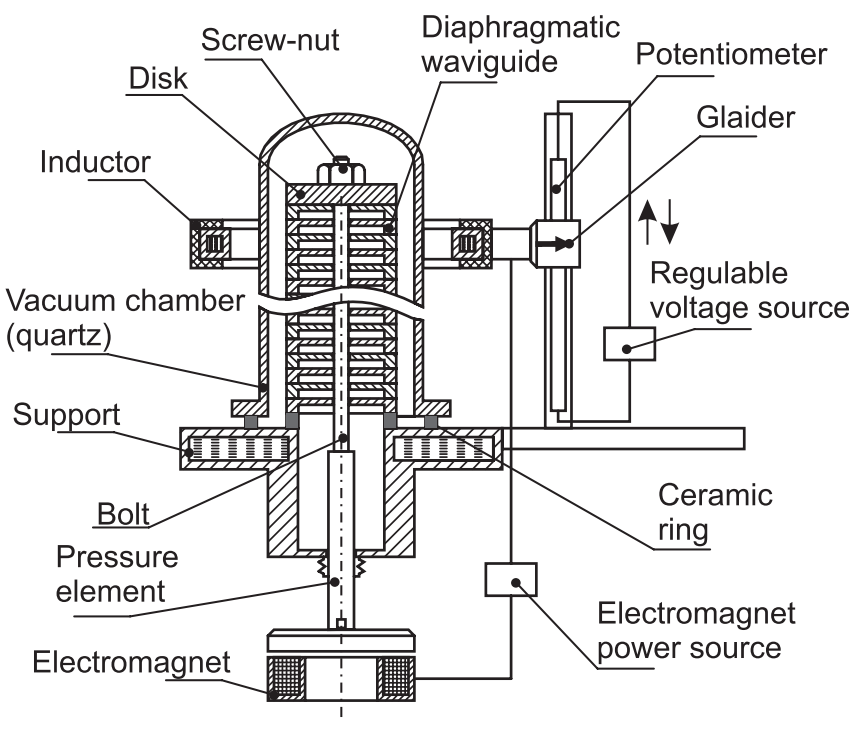

FIG. 1. Schematic view of facility for accelerating sections joining.

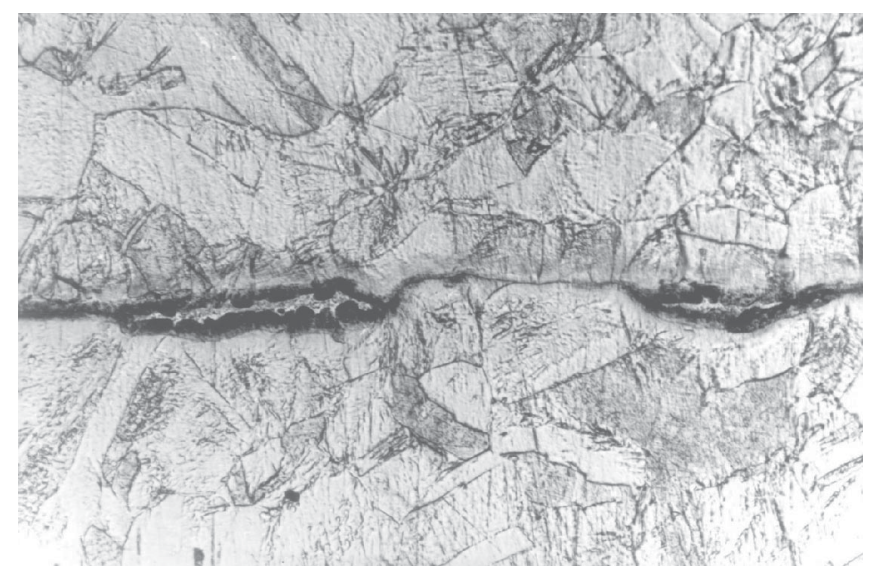

FIG. 2. Microstructure zone of joining copper-silver-copper $(\times 200)$.

diffusion brazing of two copper cells through the fluid phase of the silver $\mathrm{Cu}-\mathrm{Ag}-\mathrm{Cu}$ ). Constancy of joining process time is provided by heater appropriate dimensions and the speed of its travel. Constancy of heating temperature is provided by a gradual decrease of the heat source power during the heater top-down travel. Figure 2 shows the microstructure zone of joining of copper with copper through the pure silver coating by the galvanic method.

\section{STUDY OF FORMATION CONDITIONS OF COPPER DIFFUSION JOINT WITH MINIMAL RESIDUAL PLASTIC STRAIN}

The diffusion joint of copper in the vacuum or rare gas environment does not impose any special difficulties. However, it should be mentioned that there is no consensus over optimum parameters of copper diffusion welding
[6,7]. In order to find the optimal conditions that provide joints with a minimal residual plastic strain, the impact of surface preparation and regime parameters on mechanical properties of diffusion joints has been studied. The study has been carried out on copper samples (Russian copper marked M1) with the following dimensions: diameter $-18 \mathrm{~mm}$, height $-30 \mathrm{~mm}$. The process parameters varied within the following limits:

$\begin{array}{lll}\text { Welding pressure } & P[\mathrm{MPa}] & 1-8 \\ \text { Welding temperature } & T[\mathrm{~K}] & 973-1173 \\ \text { Welding time } & \tau[\mathrm{min}] & 5-20\end{array}$

The abutting surfaces of the samples have been processed with diamond cutters until roughness $R a=0.2$ and $0.025 \mu \mathrm{m}$. An analysis of the influence of $\sigma$ (joint strength) on the joining temperature shows that a more intensive increase of residual plastic strain $\varepsilon=$ $\Delta l / l \times 100 \%(\Delta l$ is the absolute contraction, and $l$ is the common length of welded samples) occurs at $T \geq 1073 \mathrm{~K}$, and the joint strength at this temperature reaches that of the base metal (Fig. 3). The geometrical dimensions of samples were measured before and after welding by the noncontact method (using a measuring microscope).

In the case of the high-temperature creep in the contact zone, the role of intergranular sliding increases, which, to a certain extent, contributes to formation of the physical contact. Metallographic studies demonstrate that, with the increase of the joint temperature, the number of defects in the joint zone decreases, moreover the maximal impact of the temperature increase appears at the surface roughness $R a=0.025 \mu \mathrm{m}$, in which case the formation of common (for both joining parts) grains across the joint is observed (Fig. 4).

The diagrams of dependencies of $\sigma$ and $\varepsilon$ joints on the value of welding pressure are presented in Fig. 5. It is evident from the diagrams that the increase of pressure enhances the joint strength; however, the residual strain rises steeply. The most intensive increase is observed starting with $P=4 \mathrm{MPa}$.

The experimental curves (Fig. 6) describe dependence of $\sigma$ and $\varepsilon$ joints on time, obtained for samples. Based on these curves, one can come to the following conclusion: for
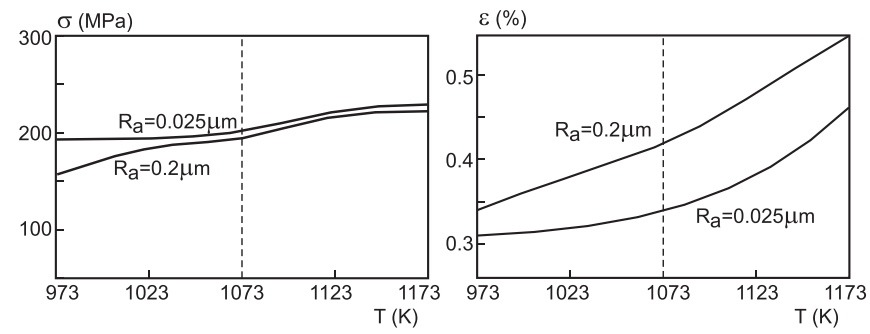

FIG. 3. Dependence of welding parameters $\sigma$ and $\varepsilon$ on the temperature $(P=4 \mathrm{MPa}, t=20 \mathrm{~min})$. 


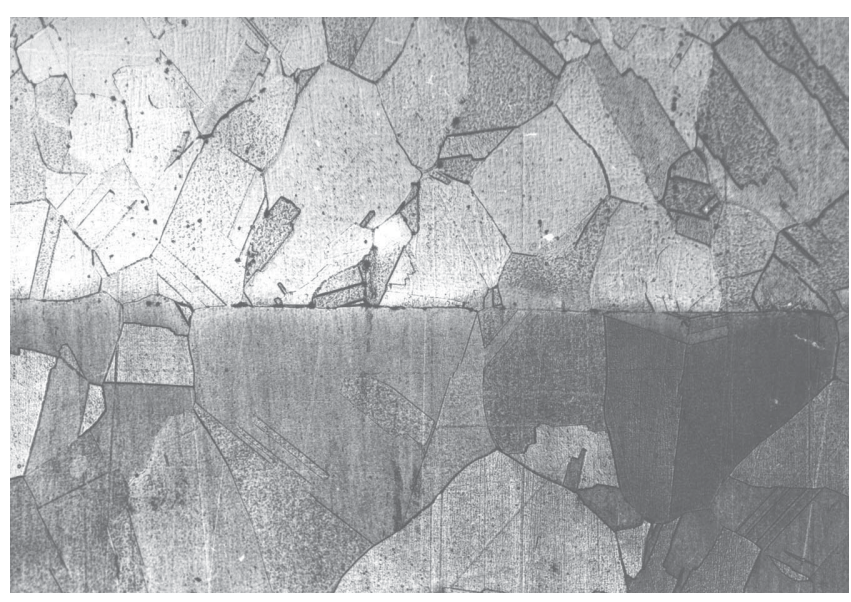

FIG. 4. Microstructure of the joint zone of joining samples $(\times 200)$ through joining parameters, $4 \mathrm{MPa}, 1073 \mathrm{~K}$, and $20 \mathrm{~min}$.

joining the real accelerator cell, more than 15 min are required.

To avoid the copper oxidation, the samples after turning were kept in vacuum. The quality of the diffusion welding of the samples, which after turning stayed in the air, was deteriorated.

In accordance with the mechanism and kinetics of the diffusion joining process, the following means of the joints' residual plastic strain reduction can be mentioned: (i) improvement of the surface roughness; (ii) preventing the surface from oxidation.

The study of the diffusion joint on two copper oxygenfree cells (with $105 \mathrm{~mm}$ diameter and $33 \mathrm{~mm}$ height) shows
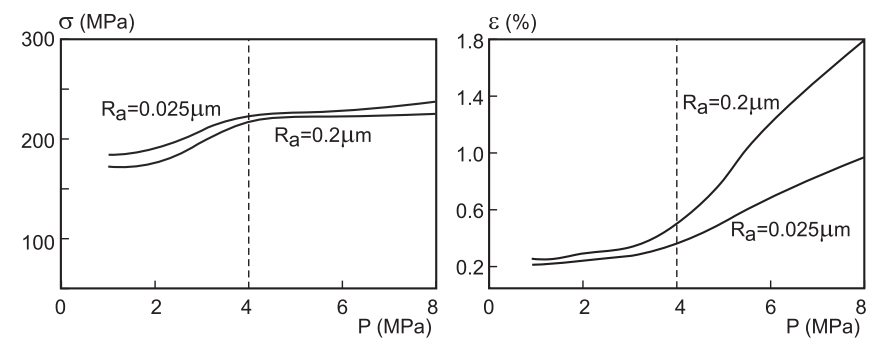

FIG. 5. Dependence of welding parameters $\sigma$ and $\varepsilon$ on welding pressure $(T=1123 \mathrm{~K}, t=20 \mathrm{~min})$.
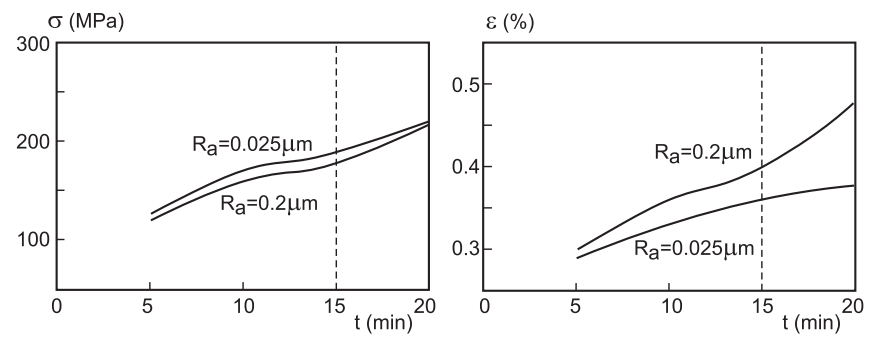

FIG. 6. Dependence of welding parameters $\sigma$ and $\varepsilon$ on time ( $T=1123 \mathrm{~K}, P=4 \mathrm{MPa})$.

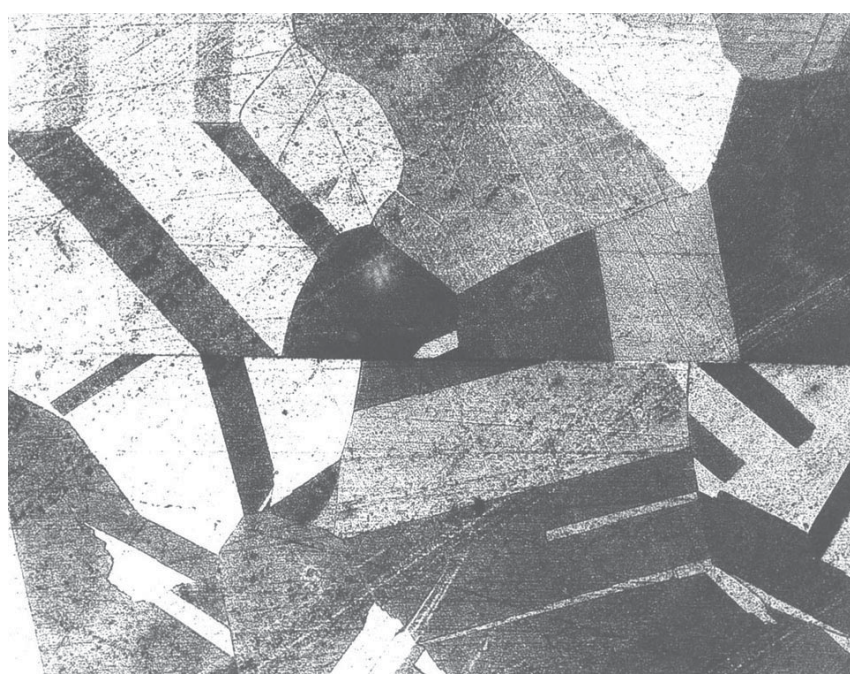

FIG. 7. Microstructure of the joint zone of joining accelerator cells $(\times 200)$ through joining parameters, $1 \mathrm{MPa}, 1073 \mathrm{~K}$, and $15 \mathrm{~min}$.

that the optimal regime parameters are

$$
T=1073 \mathrm{~K} ; \quad P=1 \mathrm{MPa} ; \quad \tau=15 \mathrm{~min} ;
$$

at the surface roughness $R a=0.025 \mu \mathrm{m}$ and the parallelism of two cell surfaces being joined is better than $0.01 \mathrm{~mm}$. It should be noticed that, before the final processing of the cell surfaces, the vacuum annealing of the cell was made. Meanwhile the relative strain is $\varepsilon=0.1 \%$. The value of pressure (1 MPa) is taken from the curve in Fig. 5 (left). As it follows from the figure, the joining parameter $\sigma$ is large enough for the given pressure. Figure 7 presents the metallographic study of the joint zone. As it is evident from the Fig. 7, the separating boundary layer remains, but its width is of the same order as that of an intergranular boundary layer. The joint strength is $\sigma \geq 180 \mathrm{MPa}$.

\section{FACILITY TO BOND PREBONDED STRUCTURES TO MAKE LONGER STRUCTURE}

In order to solve the question of Hermiticity of separate parts of the accelerating sections, a facility has been developed (Fig. 8) that makes it possible to keep under the pressure the junction area of joining parts of the sections

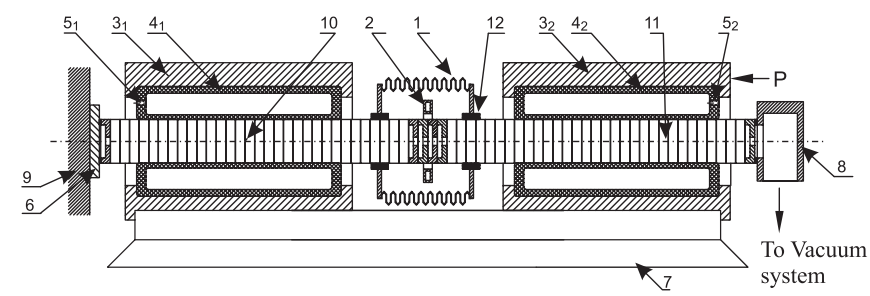

FIG. 8. Diagram of facility for diffusion welding of longlength items. 
and to control the Hermiticity during the joining process with the help of a vacuum chamber in the form of a bellows [8].

The facility consists of a vacuum chamber 1 , a heating inductor 2, a circular drum 3, a rubber wheel 4 with air supply hole 5 , a cap 6 , a base 7 , a flange 8 , a support 9 , abutting accelerating sections 10 and 11 , and a layer 12 .

The facility operates as follows. The abutting accelerating sections 10 and 11 are installed inside the drum 3 through the rubber wheel 4 . Through the hole 5 the air is supplied into the rubber chamber cavity and the pressure is applied that entraps the abutting accelerating sections, regardless of their external profiles, and provides uniform entrapment of the abutting sections, thus excluding their strain. The section 10 bears on the support 9, and the section 11 is connected with the vacuum system through the flange 8 . The circular drums $3_{1}$ and $3_{2}$ are able to move in three directions (not shown on the diagram).

After creating a vacuum in the chamber 1 , the abutting sections are heated with the help of inductor 2 until the necessary temperature, and the pressure of the joint is provided though the drum $3_{2}$ (the pressure creation mechanism is not shown on the diagram). The mutual movement of the sections 10 and 11 is provided with the help of the vacuum chamber in the form of a bellows.

The developed facility provides Hermiticity control during the joining process, passing the helium in the camera 1, and the mass spectrometer is connected to the vacuum system through the flange 8 for Hermiticity control.

\section{CONCLUSIONS}

(1) A special-purpose facility for realization of diffusion joining in vacuum is developed. The facility allows the preservation of the constant welding pressure along the full length of the waveguide for every adjacent junction of cells due to interconnection of heater movement and compression system.
(2) Optimal conditions of obtaining a joint with minimal residual strain in connection with the process parameters are determined.

(3) A vacuum facility to join accelerating sections with simultaneous vacuum Hermiticity control at the junction of adjacent sections has been developed.

\section{ACKNOWLEDGMENTS}

The work was done in Yerevan Physics Institute (Yerevan, Armenia) and in the E.O. Paton Electric Welding Institute (Kiev, Ukraine).

[1] J. Wang and T. Higo, Accelerator Structure Development for NLC/GLC, IGFA Beam Dynamics Newsletter, No. 32, pp. 27-46.

[2] Y. Higasy et al., KEK Report No. 2000-2, 2000, A/H (in Japanese).

[3] G. Carron et al., "Design of a 3GNZ Accelerator Structure for the CLIC Test Facility (CTF 3) Drive Beam," XX International Linac Conference, 2000.

[4] J. Takahashi, M.N. Martins, J. A. de Lima, A. A. Malafronte, L. Portante, M.T.F. da Cruz, and P.R. Pascholati, in Proceedings of the 1997 Particle Accelerator Conference, Vancouver, British Columbia, Canada, 1997 (IEEE, Piscataway, NJ, 1997), pp. 29983000.

[5] V.Sh. Avagyan and A.Z. Babayan, Facility for Diffusion Welding, 1755481, MK b23K 20/26, Certificate of authorship.

[6] G. V. Konyushkov, Machine Welding, 1985, No. 8, p. 2528, Kiev, Ukraine (in Russian).

[7] S. A. Sergeev and A. G. Filipenko New Welding Methods In Engineering and Instrument-Making (Saratov Polytechnic Institute, Saratov, Russia, 1988), pp. 33-36 (in Russian).

[8] V.Sh. Avagyan, Facility for Diffusion Welding of LongLength Items, Patent AM, N 1534A2, 20.04.2004, published 11.05.2004, N5 (46). 